\title{
COMPASS MEASUREMENT - STILL A SUITABLE SURVEYING METHOD IN SPECIFIC CONDITIONS
}

\author{
Julián TOMAŠTIK ${ }^{1}$, Daniel TUNÁK ${ }^{2}$ \\ Department of forest management and geodesy, Technical University, \\ T. G. Masaryka 24, 96053 Zvolen, Slovakia \\ E-mails: ${ }^{1}$ tomastik@tuzvo.sk (corresponding author); ${ }^{2}$ tunak@tuzvo.sk \\ Received 26 September 2014; accepted 9 March 2015
}

\begin{abstract}
The compass measurement is one of the customary surveying methods that is used almost from the beginning of systematic geodesy and cartography. After the periods of the decreased use of this method, it was partially renewed by the ascension of the Field-Map technology that connects the compass measurement with the software tools for the environment mapping. It is currently mostly used for the forestry under-canopy mapping and other special tasks, where the current progressive technologies, especially photogrammetry and GNSS, can be used only with complication. The Field-Map set can include either the laser rangefinder Impulse LR 200 with MapStar Compass Module II compass, or TruPulse laser rangefinder that allows also the azimuth measurement. The research was aimed on the accuracy of mentioned devices. The measured lengths and azimuth were evaluated primarily. The evaluation of the field condition results showed the mean length error 0.07-0.09 $\mathrm{m}$ for Impulse rangefinder, while 0.25-0.29 $\mathrm{m}$ for TruPulse rangefinder. The mean azimuth error was around 0.5 degree for MapStar compass and above 3 degrees for TruPulse. After this basic evaluation the data were used for the computation of four compass traverses using various measurement and computation methods. The results showed, that the compass measurement, especially using the Impulse + MapStar set, can be still a suitable method for lower accuracy surveying, although effective only in specific conditions.
\end{abstract}

Keywords: compass measurement, Field-Map, accuracy, forestry mapping, laser rangefinder, electronic compass.

\section{Introduction}

The use of compass measurement as a surveying method gradually decreased in the past. It was caused mainly by the increased number of the objects that interfere with the Earth's natural magnetism in urbanized areas and by the rise of new technologies in the last periods, especially photogrammetry and GNSS. The ascension of the Field-Map technology caused a renaissance of compass measurement as a distinctive method used in forestry under-canopy mapping and some other specific tasks. It is currently increasingly used in non-geodetic forestry tasks, such as national forest inventory (O'Donovan 2007; Buksha et al. 2010), forests research (Cienciala et al. 2013), and the like. The technology of terrestrial and airborne laser scanning could complement or even substitute the use of the compass measurement for this type of tas$\mathrm{ks}$ in the future, but there is still a need to resolve a number of technological and methodological problems (see e.g. Smreček, Danihelová 2013; Hackenberg et al. 2014). Another option could be the indoor positioning systems (e.g. Mautz 2009; Curran et al. 2011), but the main disadvantages - low accuracy, sophisticated infrastructures, limited coverage area and inadequate acquisition costs - remain unsolved despite the partial progress.

The main focus when determining the compass measurement accuracy should be on primary measured parameters, i.e. lengths and azimuths. They represent the polar coordinates of each point and their errors cause the positional shift. Višňovský and Čihal (1985) derived the equation for the positional shift of the last point of the compass traverse:

$$
q=0.004 \sqrt{d \cdot s}
$$

where $d$ is the total length of the compass traverse and $s$ is the average side length. The 0.004 coefficient 
takes the standard errors of the azimuths and lengths into account when using the devices available at that time. For the length measurement it was the error $\pm 25 \mathrm{~cm}$ at $100 \mathrm{~m}$ using the stadia rangefinder, causing the longitudinal displacement. For azimuth measurement the error was 10, which caused lateral displacement $29 \mathrm{~cm}$ at $100 \mathrm{~m}$.

The primary objective of this work was to assess the accuracy and usefulness of the compass measurement using the electronic devices, which are part of the Field-Map sets. Sub-tasks were to determine the accuracy of the measured azimuths and lengths, and then determine the overall positional accuracy based on the values of the positional shift of the last compass traverse break-point and mean coordinate errors. Thereafter assess the usability of examined measurement for various tasks by comparing these values with the prescribed criteria.

\section{Materials and methods}

The Field-Map set is modular and its components can be changed according to user needs. In principle it consists of surveying equipment to measure angle and length, support (tripod) and field computer with FieldMap software. Optionally it may include the GNSS receiver. The devices for the compass measurements are: (i) TruPulse 360B laser rangefinder that also allows the azimuth measurement or (ii) the set of Impulse LR200 laser rangefinder and MapStar Compass Module II compass. These tools combined with the simple support (monopod) were used in the present research. Field computer was not used because the format of recorded data would not allow their analysis.

When examining the used electronic devices it is clear already by using the manufacturer provided data that some changes in terms of accuracy have occurred. For the Impulse LR200 rangefinder the manufacturer specifies the length error $3 \mathrm{~cm}$ at $50 \mathrm{~m}$ and $5 \mathrm{~cm}$ at $150 \mathrm{~m}$, which varies according to the target quality. It is, therefore, a positive change over the use of stadia rangefinder. For the MapStar Compass Module II compass the manufacturer declares the \pm 0.3 degree error that is about 20. This value is two times worse than the stated error of older devices and at $100 \mathrm{~m}$ it causes the lateral displacement of $0.52 \mathrm{~m}$. After substituting these values declared by the manufacturer, the equation for calculating the positional shift changes to:

$$
q_{\text {impulse }}=0.006 \sqrt{d \cdot s} .
$$

For the TruPulse 360B device the declared error values are even higher. For the length measurement manufacturer declares the value $\pm 30 \mathrm{~cm}$ for targets designated by the manufacturer as "typical". These are probably targets with good reflectivity, but it is not stated to which measured length the error applies. For "very far" targets with less reflectivity the manufacturer declares the value $\pm 1 \mathrm{~m}$. The value $\pm 30 \mathrm{~cm}$ at $100 \mathrm{~m}$ was used for the purpose of adjusting the positional shift equation. For the azimuths measurement, the manufacturer declares the mean error \pm 1 degree. This is a value where it is very difficult to talk about the use in geodesy, as at 100 meters of measured length it causes lateral displacement $1.75 \mathrm{~m}$. However, such a value could be suitable for other applications, in particular in combination with shorter lengths of measured sides. Using these values to calculate the mean error coefficient in the positional shift equation it can be modified as follows:

$$
q_{\text {trupulse }}=0.018 \sqrt{d \cdot s} .
$$

According to the above equations, it is clear that the accuracy of compass measurement using new electronic devices is lower to the to conventional compass measurement devices already according to the values declared by the manufacturer. This is mainly caused by the lower azimuth measurement accuracy.

The above equations represent the theoretically achievable accuracy in the use of these types of devices. It is questionable in what conditions were the manufacturer declared values achieved and therefore it is very important to verify them through the practical measurement. Two point fields were designed to meet this goal in the first phase of experiment, separately for lengths measurement and separately for azimuths measurement. The point field on the straight part of the road in Technical University in Zvolen areal was used for the lengths measurement. It consisted of device occupation point and 11 points, which were at distances 5,10 meters and in 10 meter intervals up to 100 meters. Maximum length was chosen because of the small magnification of the optics used in specified devices and because the use of monopod, where the lack of precise stabilization complicates the measurement of longer distances. Also the Technical guide of the forest management (1984) declares the maximum side length of the compass traverse to $70 \mathrm{~m}$, but this was required when using conventional devices for compass measurement. Points were set out using the combination of measuring tape and TOPCON GPT3002 total station. Despite the multiple measurements, the lengths cannot be stated as absolutely precise and it is needed to take 
the $1-2 \mathrm{~cm}$ error into the account, especially for those more remote points. Points have been set out in two lines in order to allow the measurement of two alternative lengths. This procedure was chosen in order to avoid any potential memory effect of the rangefinder when measuring the same length. The measurement device and also reflective prisms were built on tripod.

The measurement of exact azimuth values is quite difficult, because these vary with place and time. All systematic errors in their measurements, however, can be removed by taking the value of the orientation deviation into account, which essentially represents the difference between the azimuth and the grid bearing determined for fixed geodetic points. The determination of the orientation deviation, which incorporates magnetic declination and meridian convergence, should be the part of every evaluation of the compass measurement (Žíhlavník 2009). The simple point field, consisting of device occupation point and 4 points, was also designed for the purpose of determining the azimuth measurement accuracy. These points were situated approximately in the 4 cardinal directions. First point was stabilized approximately in the North direction and the other 3 were set out with $100 \mathrm{~g}$ offset using the total station. Points were stabilized at a distance of about $10 \mathrm{~m}$ from the device occupation
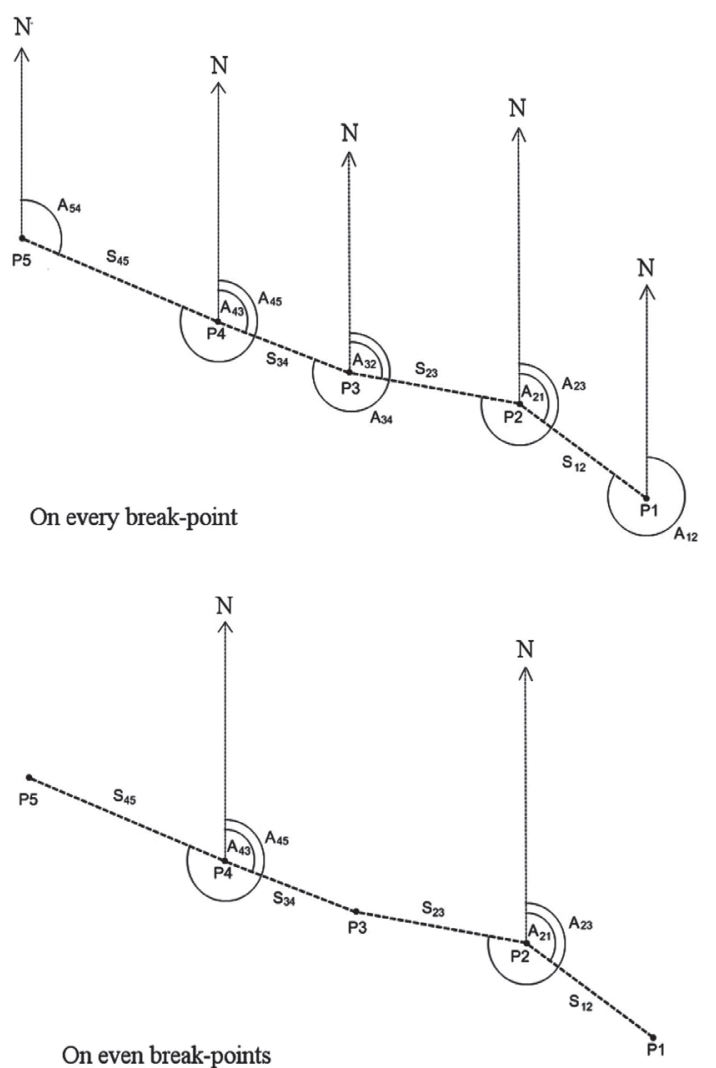

Fig. 1. Two methods of compass traverse measurement point to avoid the ambiguity when targeting as much as possible. The device has been built on tripod to limit the impact of imperfect centration, leveling and other errors which occur when measuring with the use of simple support (monopod), respectively free-hand.

The basis of compass measurement is a compass traverse, which presents the polygonal line, where the mutually independent magnetic azimuths of the traverse sides are measured.

There are basically two main methods of compass traverse measurement:

- measurement on each traverse break-point

- measurement on even traverse break-points, measurement "with skipping".

When measuring using the first method on every break-point, both direct azimuth to the next point and inverted azimuth to the previous point are determined. The length of the side is also measured two times. Due to the higher labor intensity and the need to comply with the difference criteria between direct and inverse azimuth is this method rarely applied in practice. Using the faster and more economical method of measurement on even break-point the compass measurement device is built only on each other break-point. The inverse azimuth of the previous side and direct azimuth of the next side is measured along with the side length. The next point is skipped and the device is built only at the other break-point. Reverse azimuths are converted to direct azimuths by adding or subtracting the value of $2 \mathrm{R}$. The disadvantage of this measurement method is that it is not possible to verify the correctness of the azimuth and length measurement. The principle of both methods is shown in Figure 1.

The point field that was used in the second experiment phase was founded for the purpose of verifying the accuracy of various geodetic surveying methods in the forest environment. It consists of 73 points, whereby four compass traverses with length of $772.0 ; 587.88 ; 426.33$ and $166.66 \mathrm{~m}$ were used; the number of break-points is $26,17,20$ and 8 . The point field was founded near the village Sielnica (SK), with the detailed points mainly on the borders of forest stands belonging to the University forest enterprise TU Zvolen. Individual points were stabilized using wooden or iron stakes eventually using colored cross and surveying nail. The coordinates of points were determined using the total station TOPCON GPT3002 and combination of various measurement methods (polygonal traverse, method of polar coordinates). Obtained data were used as the reference 
etalon for the compass measurement, because according to the reported standard measurement errors the total station is significantly more precise than the devices used for the compass measurement. Also, the experimental measurements confirmed the possibility of achieving centimeter accuracy using the indicated total station (e.g. Žíhlavník 2012; Žíhlavník, Tunák 2010). The point field was designed to suit the compass measurement, because in opposite to for example GNSS there is a need for intervisibility between the adjacent geodetic points. Consequently, one of the main disadvantages of the methods, which require visibility between adjacent points, is the large number of "surplus" points needed to setout a straight line in the forest. The side lengths were in range from $12.01 \mathrm{~m}$ to $84.79 \mathrm{~m}$. Overall, the side length of $60 \mathrm{~m}$ was exceeded only four times. The location of point field and the course of individual compass traverses is shown in Figure 2.

The measurement of individual compass traverses was conducted using the method of measurement on even traverse break-points, "with skipping". Using this method, the side lengths and the azimuths were measured only once, in contrast to the measurement on each break-point. The tripod was not used unlike the previous phase of the experiment. The set Impulse + MapStar was built on a monopod and the measurement was realized with enabled and disabled "Level Aid" function, which is used to level the apparatus on the stand. The measurement with TruPulse 360B took place using a monopod as well as free-hand without support. The reflective prism was placed on a pole with leveling according to the bubble level. All readings were recorded by hand in notebooks, because the Field-Map software currently does not have an option to record readings for the purposes of geodetic measurements. The orientation deviation $\mathrm{m}=8.59^{\circ}$ was determined for the transformation to the used S-JTSK coordinate system. All azimuths were modified using this value before the computation of orthogonal coordinates.

Three methods were used to determine the orthogonal coordinates of compass traverses break-points:

- the calculation of the point coordinates in succession, without adjustment;

- length adjustment of the compass traverse;

- the method of polar coordinates, using the etalon coordinates of device occupation point.

The evaluation was conducted separately for each compass traverse and after that the summary result were calculated for the entire set of surveyed points.

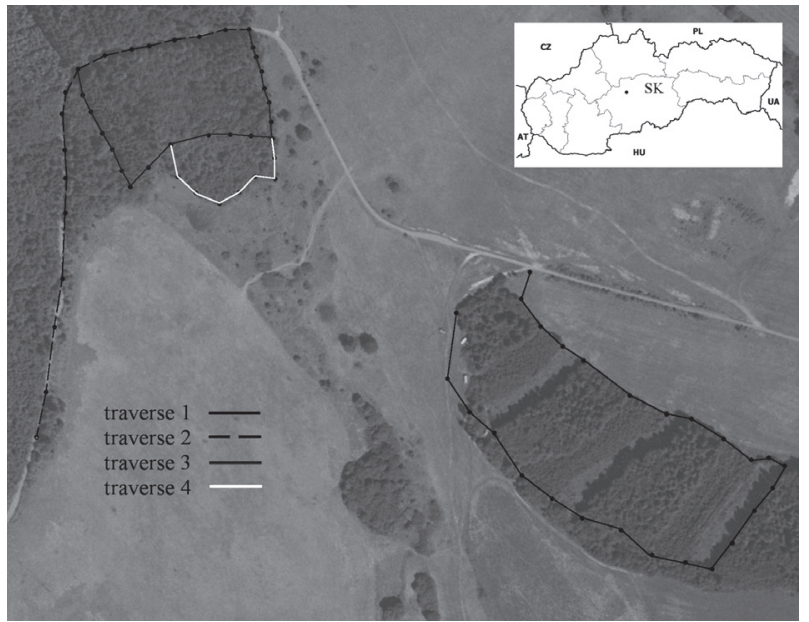

Fig. 2. The point field location and the course of individual compass traverses

The mean coordinate error $\mathrm{m}_{\mathrm{xy}}$ as well as mean errors of measured lengths and azimuths were used as basic comparative values for individual compass traverses, as well as the methods of measurement and evaluation. Those were calculated as the difference between the etalon values and the values acquired using the FieldMap set.

\section{Results}

Each length of the first phase experimental point field was measured 30 times. Subsequently, the average value, the error of average value and the standard deviation were calculated. Obtained values are shown in Table 1.

Table 1. Average values, average value errors and standard deviation of obtained lengths according to used device [m]

\begin{tabular}{|c|c|c|c|c|c|c|}
\hline \multirow{2}{*}{ Length } & \multicolumn{3}{|c|}{ Impulse LR200 } & \multicolumn{3}{c|}{ Trupulse 360B } \\
\cline { 2 - 7 } & $\overline{\mathcal{S}}$ & $\varepsilon \overline{\boldsymbol{S}}$ & $\sigma$ & $\overline{\boldsymbol{s}}$ & $\varepsilon \overline{\boldsymbol{S}}$ & $\sigma$ \\
\hline 5 & 4.98 & -0.02 & 0.06 & 5.08 & 0.08 & 0.2 \\
\hline 10 & 9.95 & -0.05 & 0.03 & 9.99 & -0.01 & 0.16 \\
\hline 20 & 19.94 & -0.06 & 0.01 & 19.88 & -0.12 & 0.11 \\
\hline 30 & 29.97 & -0.03 & 0.01 & 29.89 & -0.11 & 0.07 \\
\hline 40 & 39.98 & -0.02 & 0.01 & 39.92 & -0.08 & 0.05 \\
\hline 50 & 49.97 & -0.03 & 0.01 & 49.98 & -0.02 & 0.06 \\
\hline 60 & 60.01 & 0.01 & 0.01 & 60 & 0.00 & 0.05 \\
\hline 70 & 70 & 0 & 0.01 & 70.03 & 0.03 & 0.05 \\
\hline 80 & 80.01 & 0.01 & 0.01 & 80.03 & 0.03 & 0.05 \\
\hline 90 & 90 & 0 & 0.01 & 90.02 & 0.02 & 0.05 \\
\hline 100 & 99.98 & -0.02 & 0.01 & 100.05 & 0.05 & 0.05 \\
\hline
\end{tabular}


From the data shown, especially after taking the etalon point field error into account, it is obvious that used rangefinders achieved rather good results. It is important to note that the Impulse LR 200 length resolution is $0.01 \mathrm{~m}$, while for TruPulse $360 \mathrm{~B}$ it is $0.1 \mathrm{~m}$. The values of lengths error were tested for the presence of the bias using the Student t-test. The critical value $t_{0,05(29)}=2.045$ was repeatedly exceeded during the individual lengths tests using the values obtained by Impulse LR200, as well as TruPulse 360B. It could be generalized that lengths up to $60 \mathrm{~m}$ are slightly underrated, while lengths over $70 \mathrm{~m}$ are slightly overrated using the TruPulse 360B. This is also evident from Table 1. In most cases, however, the values are below $0.1 \mathrm{~m}$, what is the TruPulse 360B length resolution. The test criterion was also similarly exceeded using the Impulse LR200. However, the average length errors were relatively small. At such as low values it is necessary to consider the errors of etalon lengths. Overall, it can be concluded that the accuracy of length measurement did not exceed the values stated by the manufacturer. However, it must be remembered that these are the values obtained using a tripod and reflective prism. Both devices have the ability to measure lengths without the reflective prism, but it is often very problematic, especially in forest area.

Table 2. Average values, standard deviations and reduced differences of obtained azimuths according to used device

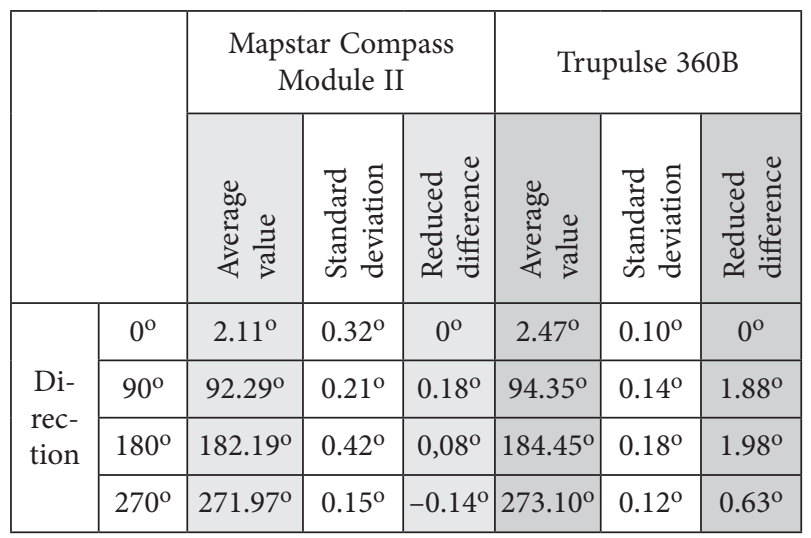

Table 3. Mean squared errors of azimuths and lengths according to measurement variant

\begin{tabular}{|c|c|c|c|c|}
\hline \multirow{2}{*}{} & \multicolumn{2}{|c|}{$\begin{array}{c}\text { IMPULSE+ } \\
\text { MAPSTAR }\end{array}$} & \multicolumn{2}{c|}{ TRUPULSE 360B } \\
\cline { 2 - 5 } & $\begin{array}{c}\text { without } \\
\text { leveling }\end{array}$ & $\begin{array}{c}\text { with } \\
\text { leveling }\end{array}$ & monopod & $\begin{array}{c}\text { without } \\
\text { support }\end{array}$ \\
\hline $\begin{array}{c}\text { Azimuth } \\
\left({ }^{\circ}\right)\end{array}$ & 0.51 & 0.48 & 3.12 & 3.24 \\
\hline $\begin{array}{c}\text { Length } \\
(\mathrm{m})\end{array}$ & 0.09 & 0.07 & 0.25 & 0.29 \\
\hline
\end{tabular}

The azimuth measurement in first phase of experiment was conducted 30 times in all 4 directions. Computed average values of azimuths, standard deviations and reduced differences are noted in Table 2. The reduced differences were calculated using the average value of first azimuth and consequently the basic direction value.

At a superficial analysis of these values, it would appear that the MapStar Compass Module II is less precise, since the dispersion of individual measurements around the average value is higher. However, when comparing the values of reduced azimuths, it is obvious that using the MapStar compass the highest difference is 0.18 degree, in opposite to 1.98 degree using TruPulse. The result is that the Mapstar compass measurements were more or less consistent in whole circle range, but TruPulse acquired azimuths which were 2 degrees higher in $90^{\circ}$ and $180^{\circ}$ directions in comparison with the other two directions. Nor the recommended calibration did help. It shifted the angles systematically, but the differences in each direction remained unchanged. Also, the measurements at another site confirmed this fact. As there was no opportunity to compare this measurement with the other measurement using device of the same type, it would be wrong to generalize these results. However, if confirmed, this would be a serious complication, because an error of this nature is hardly removable by user. The result of the first phase of the experiment confirmed that the precisions indicated by the manufacturer are real, but the measurement of shorter lengths for both types of devices and inconsistent azimuth measurement using the TruPulse $360 \mathrm{~B}$ is problematic.

Four compass traverses with different total length and average length of the side were used in the second phase of the experiment. Obtained results present the average values of 4 measurements, conducted in 20102014. As mentioned, when determining the accuracy of surveying equipment it is necessary to determine the accuracy of the primary obtained parameters first, which were the lengths and angles in this case. The length and azimuth errors were calculated for each side of used compass traverses. The mean squared error for each variant of measurement was computed using these errors. The results are listed in Table 3.

Subsequently, the measured lengths and azimuth were used in the calculation of orthogonal coordinates of all break-points in the S-JTSK coordinate system. Three methods of calculation were used. The first was the calculation of orthogonal coordinates from polar coordinates using the occupation point coordinates 
from comparative etalon, which eliminates the transfer of errors, because the coordinates of each point are calculated separately based on the coordinates of the occupation point and measured azimuth and length. Furthermore, two methods of traverse evaluation were used - without adjustment and with length adjustment, where the break-point coordinates are calculated one after another, what leads to the transfer of errors. After the calculation of coordinates, these were compared to the etalon coordinates. Coordinate errors for each break-point and subsequently the mean coordinate errors were computed according to different methods of measurement and calculation, as is shown in Figure 3.

The above figure confirms the significant difference between the accuracy of used devices. Differences for each device with and without leveling (resp. using monopod and without using it) are minimal. It should be noted that the point field was located in a slightly warped terrain. It can be assumed that the measurement in more hilly terrain would be more affected by the correct leveling.

The presented values of mean coordinate errors $\mathrm{m}_{\mathrm{xy}}$ depend on the lengths of sides and the general compass traverse configuration and therefore cannot be regarded as universally valid. It is needed to judge the measurement accuracy of used devices according to the positional shift of the last point, as was marked above in equations (1)-(3). Višňovský and Čihal (1985) stated that the maximum deviation:

$$
q_{\max }=2.5 q
$$

will in case of connected or closed compass traverse represent the allowable misclosure of numerically solved compass traverse. Therefore, misclosures of every compass traverse were determined according to the measurement method. At the same time, the expected values of the position shift $q$ were calculated according to the equations (2) and (3) for each compass traverse and used device. These values are shown in Table 4.

The results showed that the maximum deviation, equal to $2.5 q$ was not exceeded in either case. Using the Impulse + MapStar set misclosure was 0.7 to 2.2 times higher than the predicted positional shift, using TruPulse $360 \mathrm{~B} 0.3$ to 2.0 times higher. The results also showed that equations (2) and (3) are suitable for the prediction of compass measurement accuracy with the use of examined measurement devices. Of course, the reliability of this conclusion should be confirmed by additional measurements of compass traverses with different overall lengths and average side lengths.

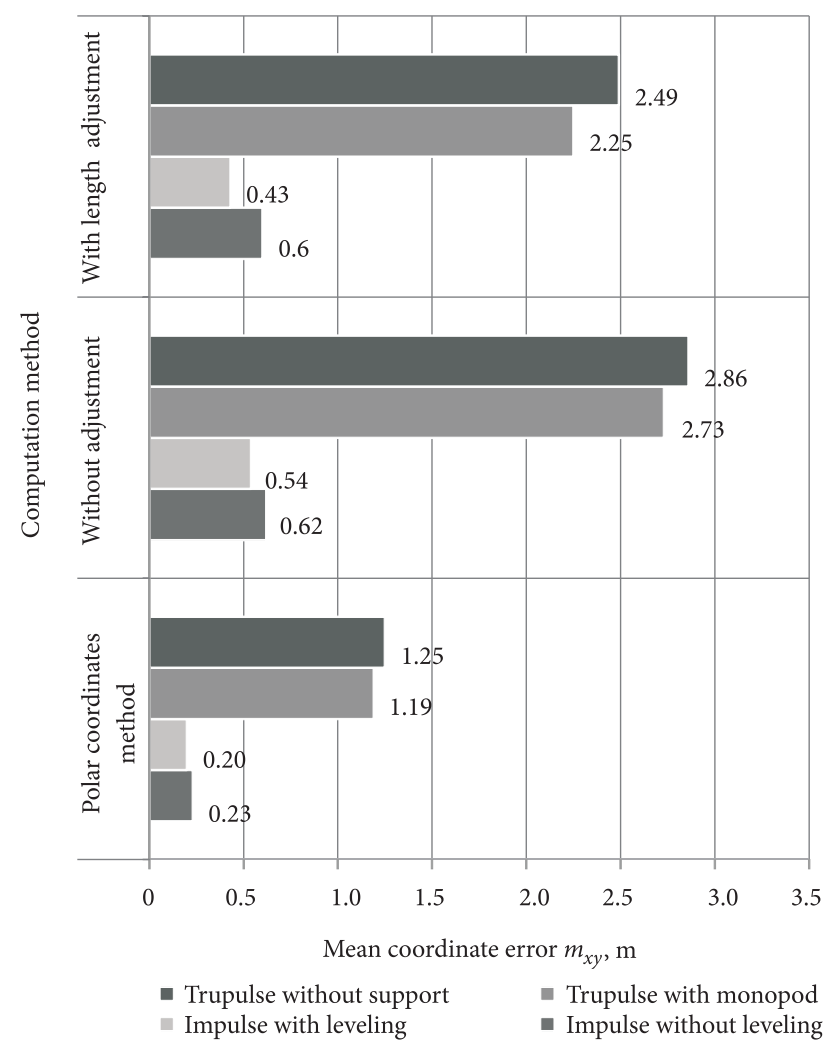

Fig. 3. Mean coordinate error values according to measurement and computation method

Table 4. Basic characteristics of experimental compass traverses, predicted positional shifts and obtained positional misclosures according to used equipment and measurement variant $[\mathrm{m}]$

\begin{tabular}{|c|c|c|c|c|c|}
\hline & & Traverse 1 & Traverse 2 & Traverse 3 & Traverse 4 \\
\hline & $\begin{array}{l}\text { Total } \\
\text { traverse } \\
\text { length }\end{array}$ & 772.00 & 587.88 & 426.33 & 166.66 \\
\hline & $\begin{array}{l}\text { Average } \\
\text { side } \\
\text { length }\end{array}$ & 32.17 & 36.74 & 22.44 & 20.83 \\
\hline & $q_{\text {impulse }}$ & 0,95 & 0.88 & 0.59 & 0.35 \\
\hline 苛 & $\begin{array}{l}\text { Impulse } \\
\text { without } \\
\text { leveling }\end{array}$ & 0.65 & 1.16 & 0.82 & 0.77 \\
\hline 总 & $\begin{array}{l}\text { Impulse } \\
\text { with } \\
\text { leveling }\end{array}$ & 0.73 & 0.99 & 0.98 & 0.69 \\
\hline & $q_{\text {trupulse }}$ & 2.84 & 2.65 & 1.76 & 1.06 \\
\hline 苛 & $\begin{array}{c}\text { Trupulse } \\
\text { with } \\
\text { monopod }\end{array}$ & 2.98 & 4.38 & 0.52 & 1.52 \\
\hline 离 & $\begin{array}{l}\text { Trupulse } \\
\text { without } \\
\text { support }\end{array}$ & 5.46 & 5.4 & 0.89 & 1.92 \\
\hline
\end{tabular}




\section{Discussion}

The obtained values provide information on practically achievable frameworks of errors that may be expected with $68 \%$ probability when using examined devices. The resulting mean error may still contain the random and systematic part. Random component decreases with increasing number of measurements, but the systematic component (the so-called bias) remains constant. Therefore, when using the surveying equipment, it is necessary to determine the presence of systematic errors, and if present eliminate it. The methodology of the study was adapted to this requirement.

Just a few authors devote themselves to the evaluation of compass measurement at the present. For example Potočnik (2010) compares the compass measurement with Suntoo to the measurement with total station and two different GNSS receivers. He assesses the compass measurement as quick and easy, but with low accuracy. Šebeň et al. (2006) reported the maximum length error up to $10 \mathrm{~cm}$ with the use of Field-Map set including Impulse LR200 rangefinder. Azimuth measurement accuracy was not engaged. They evaluate the consequences of errors of measured lengths in forest inventory, where inaccurately measured radius of circular inventory plots (even with $1 \mathrm{~cm}$ error) can significantly distort the results derived from the inventory plot data. Ruan (1995) deals with the transfer from graphic to analytic evaluation of compass traverse, but works with an ordinary compass. The paper published by Brach et al. (2013) contains the methodology and uses the equipment that is closest to the one used in the presented paper. Authors achieved almost the same results in terms of mean errors of length and azimuth and also the alike mean coordinate error.

In general, the examined devices achieved lower accuracy in comparison to older device for compass measurement. It is clear already from the accuracy values provided by the manufacturer. When measuring lengths using the both devices, paradoxically, the highest deviations and variances were achieved at lower lengths. When using the Impulse LR200 rangefinder, the reason could be in the mismatch of telescope axis and measurement laser. For lengths up to about 25 meters there is a need to place the aiming crosshair more or less above the reflective prism, thereby increasing the ambiguity of the aims and apparently affecting the elevation angle, which is used in the calculation of the horizontal distance. When using the TruPulse $360 \mathrm{~B}$, this problem is not so significant, but nevertheless errors are larger at lower lengths. This finding is important, because the standard tasks where Field-Map sets are used, often require the measurement of lower lengths. Also the principle of the compass measurement described in equations (1)-(3) says, that in contrast to polygonal traverse, compass traverse is more precise when the sides are shorter.

The evaluation of values achieved through the practical measurement of compass traverses showed, that the values for Impulse + Mapstar set are twice as high as the value specified by the manufacturer. However, it should be considered that the value of the resulting measurement error includes not only the error of the device itself, but also a variety of other errors, e.g. imperfect leveling error, imprecise targeting, noncentric emplacement of the device and the target, and so on. Similarly, the comparative etalon values cannot be stated as absolutely accurate, even when obtained using the devices with rather high accuracy. Comparing to the conventional devices for compass measurement, it can be stated that the mentioned Impulse + Mapstar set achieves better results for the lengths measurement, but only about 3 times worse results for azimuth measurement. Using TruPulse 360B, the length measurement error matches the value stated by the manufacturer and is comparable to the values achievable using the stadia rangefinders. In contrast, the azimuth error is very high. The value above 3 degrees would virtually rule the possibility of using the device for surveying tasks out and also the use for other purposes would be very questionable. Apparently the combination of azimuths of the compass traverses sides in conjunction with the inconsistent measurement caused such a high error. Besides that, it is not a systematic error, since the critical value for testing the bias was not exceeded. The existence and the possible solution of such a high error must be confirmed through the more future measurements.

Comparing the evaluation methods, the polar method with the use of etalon coordinates of occupation points was confirmed as the most accurate. In practice, this method could be used in a combination of the mentioned devices with other surveying methods, where the position of the occupation point would be determined by more accurate method (e.g. GNSS) and the surrounding topography would be measured using noted devices. It is important that with this method, the measured points (resp. azimuths and lengths) do not influence each other. When using this method and the Impulse + MapStar set, the criterion for the $4^{\text {th }}$ accuracy class according to the Slovak 
technical standard STN 013410 (1990) was fulfilled, which is required for the cadastral mapping outside the urbanized areas (forests, agricultural areas). The other two methods represent the traverse solution; ergo the coordinates of the points are calculated sequentially and are mutually connected. This causes the significant increase of the mean coordinate error. The calculation without adjustment is a standard procedure of the Field-Map use, where the first occupation point is a known geodetic point, but the traverse is not finished on another known point. Therefore the adjustment is not possible. The calculation with adjustment is possible when the compass traverse is inserted between two known geodetic points. In that case, the length adjustment is possible. The considerable information for the practice is, that the final accuracy within 1 meter could be achieved using the Impulse + Mapstar set, which corresponds to the sum of the traverse calculation without adjustment (establishing occupation points) and polar method (measurement of surrounding topography). The values obtained using TruPulse 360B were significantly higher. Another criterion, used in practice of Slovak forestry mapping is, that the maximum misclosure of graphically evaluated connected or closed compass traverse should not exceed the $2 \%$ of the total traverse length. However, the accuracy of the graphical evaluation is reflected in this criterion in addition to the measurement precision. For the experimental traverses this value means $15.4 \mathrm{~m}$ for traverse $1,11.8 \mathrm{~m}$ for traverse 2, $8.6 \mathrm{~m}$ for traverse 3 and $3.4 \mathrm{~m}$ for traverse 4 . The obtained real misclosures are lower than noted maximum misclosures in every case.

Based on the obtained results it can be stated that compass measurement, even when using electronic devices, may be still an applicable method for surveying tasks with lower accuracy demands. These results showed that the source of the highest errors is the azimuth measurement. These cause the lateral displacement depending on the length of the side to which was subsequently added the longitudinal displacement caused by the error of the length measurement. Thus it is confirmed, that it is preferable to choose a larger number of shorter sides when using compass measurement. The remaining advantage of compass measurement over the use of theodolites, tachymeters, respectively total station remains is the lower demand on the existing point field, because no orientation points are necessary for determining the basic direction. It is especially convenient in rural areas where the point field is sparse. Similarly advantageous is the possibility to use a monopod, which facilitates and accelerates the device stationing in the field. Despite the above result the efficient use of compass measurement is currently more or less limited only to under-canopy measurements in forests, underground areas and other areas especially with the obscure reception of GNSS signals. The reason is the high efficiency of the photogrammetric evaluation of elements that are identifiable on photogrammetric images as well as the possibility of using global navigation satellite systems. The accuracy of GNSS methods in areas with good signal reception is much higher, while the time consumption can be lower when compared to the compass measurement. The results of the evaluation method using the etalon coordinates of occupation points may show the potential for increased accuracy in combination with other methods, where the more accurate method will be used to achieve the coordinates of occupation point (e.g. GNSS) and the surrounding topography would be measured using the method of polar coordinates for compass measurement. The practical problem for using such a combination, especially in forestry mapping, is, that the linear objects, which are most widespread in forestry mapping, cannot be measured from one occupation point, while the correct determination of position using GNSS in forest is problematic.

When using the national grids, as was the SJTSK system in actual study, it is very important to include the value of the orientation deviation. It cannot be substituted by magnetic declination; the meridian convergence must be also taken into account. Therefore it is necessary to determine the orientation deviation for every compass measurement either by direct measurement (comparison of grid bearings and azimuths on the known points), or by calculating the magnetic declination and meridian convergence for the particular area.

\section{Conclusions}

The current period is characterized by an increased demand for spatial information in virtually all fields of the human activity. These are often made available to the wide public. The quality of the data, which is conditioned by their origin, is often overlooked during the process of creating and filling a variety of geographic information systems. In the process of the introduction of new technologies for obtaining these data it is therefore very important to look not only on the efficiency of their use, but also on the spatial accuracy of the data. 
With regards to the achieved results the following conclusions can be drawn:

- the mean coordinate error under $0.5 \mathrm{~m}$ can be achieved by using the Impulse + MapStar set and compass traverses with short sides and short total lengths. The results when using the TruPulse device are many time worse.

- the main source of error of examined devices is the azimuth measurement.

- the fact, that compass traverses with shorter average side lengths are more accurate, remains valid.

- it is necessary to keep clean from objects that affect the Earth's natural magnetism.

- in terms of efficiency and relative small effect of leveling choose as simple set as possible (preferably with monopod).

- it is important to take the value of orientation deviation into account when connecting the measurement into the national grid.

The compass measurement is currently mostly used in forestry research and forestry inventory. For this purpose, it is sufficiently effective and fast. The measurements in forestry research are conducted mostly in local coordinate system that is generally not necessary connected to the geodetic points. In the field of research and inventory the compass measurement successfully replaces customary surveying methods, based on the measurement method in the local orthogonal coordinate system using simple tools such as stakes and steel tape. Compared to these methods, the compass measurement with the use of laser rangefinder and electronic compass is less laborious and time-consuming. The important contribution to the application of compass measurements as an appropriate method for detecting the state of the environment is the ability to use specialized software for automated processing of measured data, which represents the perspective for the preservation and further development of tools for compass measurement. The main disadvantage is the smaller effectiveness and accuracy in most areas, where the GNSS or photogrammetry can be used. For that reason the effective use of compass measurement is currently limited to the forest under-canopy measurements and some other specific measurements (for example subterranean) where the actual most efficient methods cannot be used without complications.

\section{Acknowledgement}

This publication is the result of the implementation of the project VEGA MŠ SR and SAV no. 1/0804/14: "Actualization of mapping, arrangement of forest land ownership and determination of landscape status by modern methods of geodesy and aerial survey".

\section{References}

Brach, M.; Bielak, K.; Drozdowski, S. 2013. Measurements accuracy of selected laser rangefinders in the forest environment, Sylwan 157(9): 671-677.

Buksha, I.; Černý, M.; Buksha, M. 2010. An experience use of GIS Field-Map in forest inventory, in International Scientific - Practical Conference "New Technologies in Geodesy, Land Management and Nature", 28-30 October 2010, Uzhgorod, 142-146.

Cienciala, E.; Centeio, A.; Blazek, P.; Cruz Gomes Soares, M.; Russ, R. 2013. Estimation of stem and tree level biomass models for Prosopis juliflora/pallida applicable to multistemmed tree species, Trees 27(4): 1061-1070. http://dx.doi.org/10.1007/s00468-013-0857-1

Curran, K.; Furey, E.; Lunney, T.; Santos, J.; Woods, D.; Mc Caughey, A. 2011. An evaluation of indoor location determination technologies, Journal of Location Based Services 5(2): 61-78. http://dx.doi.org/10.1080/17489725.2011.562927

Hackenberg, J.; Morhart, Ch.; Sheppard, J.; Spiecker, H.; Disney, M. 2014. Highly accurate tree models derived from terrestrial laser scan data: a method description, Forests 5(5): 1069-1105. http://dx.doi.org/10.3390/f5051069

Lesoprojekt Zvolen. 1984. Technická príručka hospodárskej úpravy lesov [Technical guide of the forest management]. $594 \mathrm{p}$.

Mautz, R. 2009. Overview of current indoor positioning systems, Geodesy and Cartography 35(1): 18-22. http://dx.doi.org/10.3846/1392-1541.2009.35.18-22

O'Donovan, Ch. 2007. Introduction to Ireland's NFI, in National Forest Inventory Republic of Ireland - Proceedings of NFI Conference, 2007, Forest Service, Department of Agriculture, Fisheries and Food. Johnstown Castle Estate, Co. Wexford, Ireland. 93 p.

Potočnik, I. 2010. Use of various geodetic methods in forest engineering, in First Serbian Forestry Congress, 2010, University of Belgrade, Faculty of Forestry, 542-552.

Ruan, Z. 1995. An improvement on the calculative method for forest land area and an approach to the allowable error of compass traverse, Journal of Fujian Forestry Science and Technology 01/1995: 22-28.

Smreček, R.; Danihelová, Z. 2013. Forest stand height determination from low point density airborne laser scanning data in Rožňava Forest enterprise zone (Slovakia), iForest 6: 48-54

Šebeň, V.; Šmelko, Š.; Merganič, J. 2006. Skúsenosti z uplatnenia technológie Field-Map v národnej inventarizácii a monitoringu lesov SR a ich zovšeobecnenie [Experiences with the use of Field-Map technology in national forest inventory and monitoring in Slovakia], in Envirofórum 2006, 10-20 October 2006, Zvolen, 175-185

STN 01 3410: 1990. Mapy velkých mierok [Large scale maps]. Bratislava, Geodesy, Cartography and Cadastre Authority of Slovak Republic, 1990. 20 p.

Višňovský, P.; Čihal, A. 1985. Geodézia a fotogrametria [Geodesy and photogrammetry]. Bratislava: Príroda. 546 p.

Žíhlavník, Š. 2009. Geodézia, fotogrametria a mapovanie v lesnictve [Geodesy, photogrammetry and mapping in forestry]. Zvolen: Technical University in Zvolen. 387 s. 
Žíhlavník Š. 2012. Problematika katastrálneho mapovania $v$ lesných porastoch [The problems of cadastral mapping in forest stands]. Zvolen: Technical University in Zvolen. 80 p.

Žíhlavník, Š.; Tunák, D. 2010. Racionalizácia mapovacích prác využitím metódy polygónových tahov [Rationalisation of mapping works using the method of polygonal traverses]. Zvolen: Technical University in Zvolen. 83 p. $\overline{\text { Julián TOMAŠTIK, PhD. Lecturer of Geodesy and photo- }}$ grammetry, Cadastre of real estates and other. Department of Forest Management and Geodesy, Faculty of Forestry, Technical University in Zvolen, T.G. Masaryka 24, 96053 Zvolen, Slovakia.

Research interests: forestry mapping, GNSS, photogrammetry, GIS, cartography.

Daniel TUNÁK, PhD. Researcher. Department of Forest Management and Geodesy, Faculty of Forestry, Technical University in Zvolen, T.G. Masaryka 24, 96053 Zvolen, Slovakia.

Research interests: various surveying methods, forestry mapping, GNSS. 